Special Issue of the 8th International Advances in Applied Physics and Materials Science Congress (APMAS 2018)

\title{
Etchants for Chemical Machining of Aluminium and Its Alloys
}

\author{
O. ÇAKIR* \\ Yildiz Technical University, Department of Mechanical Engineering, 34349 Istanbul, Turkey
}

\begin{abstract}
Aluminium is one of the main engineering materials used extensively in aircraft and automotive industries where the weight is an important factor. Chemical machining of aluminium and its alloys has widely been studied to produce parts. Chemical machining is based on selection of optimum chemical solution which is named as etchant for shaping the required material. In this study, chemical machining of aluminium and its alloys has been surveyed to provide scientific data for industrial applications. Other chemical machining parameters such as etchant concentration, chemical machining temperature, and additives to main etchant have been extensively examined.
\end{abstract}

DOI: 10.12693/APhysPolA.135.586

PACS/topics: chemical machining, aluminium, etchant, temperature

\section{Introduction}

Chemical machining is a typical nontraditional machining method that implements strong chemical solution (etchant) to remove selectively the required section of material by controlled dissolution. It has various names like etching, chemical etching, wet etching, chemical milling, chemical blanking, etc. It is also the oldest micromachining processes, used for jewellery production from copper etched with citric acid in the Ancient Egypt [1]. The process has been heavily used since 1950 's to produce micron sized components. Nowadays it is a popular nontraditional machining method that offers unique benefits for distinct part productions for aerospace, automotive, medical, and optic industries [2].

Aluminium has a wide engineering application as a material in aircraft, aerospace, and automotive industries where high specific strength, low specific weight, heat and electrical conductivities are highly required. It has various types and each aluminum alloy has several advantages. Therefore chemical machining of aluminium and its alloys is vital.

Etchant is the major parameter in chemical machining. The selection of suitable etchant for any material affects the process performance. There is an excellent reference covering most of possible etchants for various materials, which gives initial informations relating chemical machining [3]. The ideal aluminium etchant should combine several properties such as easy control of chemical machining application, high chemical machining rate, high dissolved aluminium capacity, regeneration of used etchant, and aluminium recovery from used etchant.

In this study, the chemical machining of aluminium and its alloys is examined by detailed research of literature. It is aimed to provide possible industrial solutions when aluminium and its alloys are chemically machined.

*e-mail: orhanc@yildiz.edu.tr

\section{Etchants for aluminium and its alloys}

Aluminium is a soluble material in dilute mineral acids and alkali metal hydroxides or acid etchants. Literature provides limited information regarding these etchant types. The selection of optimum chemical etchant is complex and delivers various results. The chemical machining of aluminium and its alloys was used for decorative purposes in early applications, but industrial applications have come up around 1950's and continuously extended. Several studies have been conducted over chemical machining of aluminium [4-12]. Most of these reports mentioned limited etchants which are viable for industrial applications, while others had restricted opportunities.

Ferric chloride $\left(\mathrm{FeCl}_{3}\right)$ is a popular acidic etchant, widely used in chemical machining industry and known as universal etchant suitable for most of materials. The chemical reaction with aluminium is simple, but the used etchant will have some problems in case of regeneration and recovery of metal. The process is fast, causing control of the machining operation. Hence concentrations should be kept around $1.2-1.25 \mathrm{~mol}$. A chemical machining temperature should be also maintained low, due to high heat generation during the process. The surface quality is also poor, and rougher surfaces have been reported $[5,6]$ :

$$
3 \mathrm{FeCl}_{3}+\mathrm{Al} \rightarrow 3 \mathrm{FeCl}_{2}+\mathrm{AlCl}_{3} .
$$

Ferric nitrate $\left(\mathrm{Fe}\left(\mathrm{NO}_{3}\right)_{3}\right)$ has been reported to be a possible etchant for aluminium due to higher etch rates [7]. Again, ferric ion like in $\mathrm{FeCl}_{3}$, is converted to ferrous during dissolving metallic aluminum as the nitrate

$$
3 \mathrm{Fe}\left(\mathrm{NO}_{3}\right)_{3}+\mathrm{Al} \rightarrow 3 \mathrm{Fe}\left(\mathrm{NO}_{3}\right)_{2}+\mathrm{Al}\left(\mathrm{NO}_{3}\right)_{3} .
$$

Sodium hydroxide $(\mathrm{NaOH})$ is an alkali metal hydroxide type etchant for chemical machining of aluminium and its alloys $[6,8,9]$. This etchant provides faster machining performance comparing to $\mathrm{FeCl}_{3}$. The hydrogen existence occurs and this would be a problem. The concentration should be 1 mol. The control of chemical machining of temperature would be some of difficulties and 
temperature should be $50{ }^{\circ} \mathrm{C}$ if high machining performance is required. It was also reported that the surface quality would be better

$$
3 \mathrm{NaOH}+\mathrm{Al} \rightarrow \mathrm{Na}_{3} \mathrm{AlO}_{3}+3 / 2 \mathrm{H}_{2} .
$$

Potassium hydroxide $(\mathrm{KOH})$ can be selected as etchant and the performance in aluminium's chemical machining is similar to sodium hydroxide [8]. This etchant is useful when pure aluminium is chemically machined, but alloying elements would make the process harder [10]:

$$
3 \mathrm{KOH}+\mathrm{Al} \rightarrow \mathrm{K}_{3} \mathrm{AlO}_{3}+3 / 2 \mathrm{H}_{2} .
$$

Hydrochloric acid $(\mathrm{HCl})$ can be employed when dilute mineral acid etchant is required. It can be used alone or can be added to main etchant for extending chemical machining period. This etchant, as is reported, ensures the highest chemical machining performances [6-8]. It is noted that machining performance is better even when low temperatures are used

$$
3 \mathrm{HCl}+\mathrm{Al} \rightarrow \mathrm{AlCl}_{3}+3 / 2 \mathrm{H}_{2} .
$$

Other possible chemical etchants can be named as sulfuric acid $\left(\mathrm{H}_{2} \mathrm{SO}_{4}\right)$, nitric acid $\left(\mathrm{HNO}_{3}\right)$, alkaline potassium ferricyanide solution or mixtures of mentioned etchants like $\mathrm{FeCl}_{3}+\mathrm{HCl}$, sodium fluoride $(\mathrm{NaF})+$ chromic acid $\left(\mathrm{CrO}_{3}\right)$. Table I present mainly used etchants for chemical machining of aluminium and its alloys $[11,12]$.

TABLE I

\begin{tabular}{|c|c|c|c|c|}
\hline Etchant & Concentration & $\begin{array}{c}\text { Temp. } \\
{\left[{ }^{\circ} \mathrm{C}\right]}\end{array}$ & $\begin{array}{c}\text { Machining } \\
\text { speed } \\
{[\mu \mathrm{m} / \mathrm{min}]}\end{array}$ & $\begin{array}{c}\text { Surface } \\
\text { quality } \\
{[\mu \mathrm{m}]}\end{array}$ \\
\hline \multirow{2}{*}{$\mathrm{FeCl}_{3}$} & \multirow{2}{*}{$1.2-1.25 \mathrm{~mol}$} & 30 & 1.3 & 8 \\
\hline & & 50 & 4 & 10 \\
\hline $\mathrm{Fe}\left(\mathrm{NO}_{3}\right)_{3}$ & $50-100 \mathrm{~g} / 1$ & 50 & $0.5-1$ & - \\
\hline \multirow{2}{*}{$\mathrm{NaOH}$} & \multirow{2}{*}{$1 \mathrm{~mol}$} & 30 & 1.3 & 1.5 \\
\hline & & 50 & 4 & 3 \\
\hline \multirow{2}{*}{$\mathrm{KOH}$} & \multirow{2}{*}{$1 \mathrm{~mol}$} & 30 & 1 & 1 \\
\hline & & 50 & 2.5 & 3 \\
\hline \multirow{2}{*}{$\mathrm{HCl}$} & \multirow{2}{*}{$1 \mathrm{~mol}$} & 30 & 7 & 2 \\
\hline & & 50 & 30 & 6 \\
\hline \multirow{2}{*}{$\mathrm{HNO}_{3}$} & \multirow{2}{*}{$10: 1$ (v/v ratio) } & 30 & 0.1 & - \\
\hline & & 50 & 0.4 & - \\
\hline
\end{tabular}

Application parameters and potential results of various etchants for aluminium.

Chemical machining of aluminium and its alloys provokes some health and environmental problems: the etchant is either strong acid or alkaline solution which causes serious damages to health. The fume generation during chemical machining must be controlled and proper ventilation and personal protective equipments are necessity. Moreover, the used etchant contains several chemical elements which are listed as hazardous waste and environmental legislations are tight. Therefore chemical machining industry prefers optimum etchant that is regenerated and chemically machined material recovery $[13,14]$. The regeneration process oxides the used etchant back to starting form of solution and the machining method turns into environmental friendly manufacturing process, as well as cost-effective one.

\section{Conclusion}

Chemical machining of aluminium and its alloys have been examined with limited studies. Some works are patented, and those are also employed with similar etchants and/or some additives. Aluminium can be chemically machined by choosing any acid etchants (like $\mathrm{FeCl}_{3}$ ), alkali metal hydroxides (such as $\mathrm{NaOH}$ or $\mathrm{KOH}$ ), or dilute mineral acids $(\mathrm{HCl})$. It should be noted that the chemical reaction should be simple to control and regenerate the used etchant. Therefore, the etchant should be kept as simple as possible. The studies contributed possible etchants for this group of materials and etchant application would be performed with strictly maintained required concentration and temperature. The chemical machining process should also cover an efficient result from the point of view of environment-friendly and costeffective operations. Literature review suggested that new studies should be set to supply more efficient etchant or etchants reducing overall costs and maintaining sustainable manufacturing.

\section{References}

[1] W.T. Harris, Chemical Milling, Oxford University Press, Oxford 1974.

[2] O. Çakır, A. Yardımeden, T. Özben, in: Proc. Worldwide Congress on Materials and Manufacturing Engineering and Technology (COMMENT'2007), Poland $200 \%$.

[3] P. Walker, W.H. Tarn, Handbook of Metal Etchants, CRC Press, Florida 1991.

[4] M.C. Sanz, US Patent No: 2739047, 1956.

[5] O. Çakır, J. Mater. Process. Technol. 199, 337 (2008).

[6] D. Allen, Photochemical Machining and Photoforming, London 2015, p. 129.

[7] B. Chambers, Met. Finish. 98, 26 (2000).

[8] O. Çakır, A. Arat, M.S. Akgün, M. Kahraman, K. Kazan, T. Sis, Y. Uyar, İ.H. Ylldı, in: Proc. 15th Int. Conf. on Machine Design and Production, Denizli (Turkey) 2012, p. 1239.

[9] B. Chattergee, R.W. Thomas, Trans. Inst. Met. Finish. 54, 17 (1976).

[10] Y. Okinaka, Etch procedure for aluminum alloys, US Patent No: 4349411, Madison (NJ) 1982.

[11] H. Win, T.J. Mori, Plat. Surf. Finish. 67, 53 (1980).

[12] D.M. Allen, in: Proc. 2nd Int. 8 23rd All India Machine Tool Design Research Conf. (AIMTDR), India 2008, pp. 37.

[13] L.K. Wang, N.K. Shammas, Y.-T. Hung, Waste Treatment in the Metal Manufacturing, Forming, Coating, and Finishing Industries, CRC Press, 2009, p. 345 .

[14] R.T. Grah, Met. Finish. 101, 8 (2003). 